\title{
2121 and all that
}

\author{
Stephen Hancocks OBE \\ Editor-in-Chief
}

The BDJ Upfront section includes editorials, letters, news, book reviews and interviews. Please direct your correspondence to the News Editor,

Kate Quinlan at k.quinlan@nature.com. Press releases or articles may be edited, and should include a colour photograph if possible.

$\mathrm{T}$ he Dentists Act of 1878 created the Dentists Register, to which in the following year only the names of qualified dentists could be added. However, an unfortunate clause meant that others could practise dentistry as long as they didn't call themselves a dentist. One hundred years ago, the Dentists Act 1921 closed that loophole and brought into law the requirement that from then on only those who were actually qualified as dentists could practise dentistry. A grandparenting clause enabled anyone who could prove they had practised dentistry for five years prior to also join the Register. Consequently it was the 1970s when the last of the 'unqualified' or '1921 dentists' fully retired.

Much has changed as we recognise the centenary of what might be considered the true recognition of the dental profession in the UK. If the notion of blue-sky thinking or horizongazing existed at that time, although under different names, I would suggest that for most prophets two major differences would not have stirred their consciousness. One would be the dental team, and the other the NHS. In 1921 there was no notion whatsoever of a dental team. Indeed a Branch and Section report in the $B D J$ of the meeting of the Metropolitan Branch on 3 March 1920 noted that members in the London area were urged to offer employment to 'ex-Servicemen who had been trained at the Borough Polytechnic as dental mechanics'. However, the overwhelmingly male dominated profession (Lilian Lindsay, the first woman British dentist, qualified in 1895) were also advised that 'women dental mechanics were still being employed in connection with the Army of Occupation on the Rhine' but that the 'National Advisory Technical Committee (Dental Mechanics) had protested several months ago to this employment' to the War Office.

Despite a concurrent fourth wave of the Spanish flu pandemic affecting some countries in Europe, the dental profession seemed to be fully focused on the legislation and how it would affect its livelihood. Some things change; some things don't. Our present pandemic has caused us to question a lot of our values and beliefs across oral healthcare. This has prompted grand words from many about the state of systems and how they will need to change, adapt, develop, morph, build back better and so forth. But it is the details of systems which throw up precisely the conundrums and anomalies that directly affect the people caught in the webs of regulation. This is true not only of practice owners (primarily, although not exclusively, dentists) but also of team members. The briefest of skirmishes flashed across our 'letters' pages in the early stages of the pandemic, with one contractors for NHS dental services.

This legerdemain of bureaucratically generated word play seriously messes with people's understanding of how things work; in this case, who is actually providing what service. It also obscures clarity as to why one dentist can provide a particular treatment at a given time of the year, when another (who has no UDAs left) cannot. Further, it risks undermining the whole model of the provision of a 'health' service. Nowhere was this more starkly realised than in purely private dental practices where, effectively, the government by default, and the opposition quite openly threw practitioners under a bus. In no uncertain terms, they were told that having decided to opt out of the (NHS)

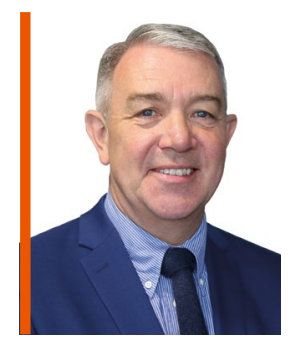

'It is the details of systems which throw up precisely the conundrums and anomalies that directly affect the people caught in the webs of regulation.' correspondent opining that the idealism of skill mix would be suffocated by the strictures of lockdowns, while another parried that, on the contrary, it was alive and well and pointed to the future.

What strikes me as being of greater consideration is learning from the experiences of the real team members who have suffered (my italics) in unforeseen ways. Dental nurses, for example, even those who worked in purely NHS dental practices, were not designated as NHS workers and were thus not entitled to the benefits extended to other NHS staff. Yet in many cases there was an expectation that they could be, and indeed were, available for redeployment. Thankfully, this sleight has been rectified but it resulted as a consequence of dentists having opted to be independent system they were therefore on their own, despite being legally restrained from trading (a key word here) and despite 'saving' the NHS money when they were trading by relieving it of demand from those receiving care.

There is a tendency for history to permit condescending forgiveness. We smile and shake our heads at the lack of apparent understanding of those colleagues huddled over the parliamentary vellum, one hundred years ago, with a perceived myopic naivety over that which was to follow. But what of us, now? How will readers of the $B D J$ in spring 2121 assess our abilities to face the future? What will become of the NHS and the dental team? Will the passage of time be kinder to us in hindsight? Female dental mechanics indeed. Pah!

https://doi.org 10.1038/s41415-021-3028-6 